\title{
Challenges Facing Adoption of Information \\ Communication Technology (ICT) In Educational Management in Schools in Kenya
}

\author{
Dr. Emmy J. Kipsoi \\ Director Institute for Gender Equity, Research \& Development (IGERD), Moi University, \\ Kenya \\ E-mail: kipsoi@yahoo.com \\ Dr. John K. Chang'ach \\ Head of Department of Educational Foundations, School of Education, Moi University, \\ Kenya \\ E-mail: jkchangach@yahoo.com
}

Hellen C. Sang

Acting Dean, School of Education and Social Sciences, Department of Curriculum, Instructional \& Education Media, Kabianga University College, Kenya E-mail: sanghellen@gmail.com

Accepted: May 5, 2012 Published: June 01, 2012

Doi:10.5296/jsr.v3i1.1882

URL: http://dx.doi.org/10.5296/jsr.v3i1.1882

\begin{abstract}
ICT has contributed greatly to educational management in schools globally (Zhao and Frank, 2003). However, in Kenya schools hardly use ICTs to manage the quality of output, or to raise teacher productivity, or to reduce costs through analyzing spending. This is attributed to a myriad of challenges facing most schools in Kenya with regard to adoption of ICTs in educational management. This has resulted to a slow rate of adoption of technology despite its promise and potential for use in educational management in schools. As such, this paper analyses the lethargy that has surrounded education management in schools with respect to
\end{abstract}


acquisition of Information Communication Technology. Education and training sector has a major role to play in the implementation of the proposed ICT policy. First, the sector itself is a major user of ICT, not only in education, training and research but also in the management of the sector. The paper argues that ICT policies must be dynamic, cost-effective, adaptable, and differentiated between sectors and between the various segments of educational management in order to contribute effectively to education management. The recommendations of this paper provide a basis for the urgent need for the integration of ICTs in educational management in schools in Kenya.

Keywords: $\quad$ Adoption, ICT, Management, Educational, Schools

\section{Introduction}

By its very nature the ICT phenomenon is relatively in the developing world. Available data, suggest that the majority of developing countries such as Kenya in sub-Saharan Africa are lagging behind in the information revolution (Zhao and Frank, 2003). Not surprisingly, the quest for adoption of ICT in educational management has been problematic and will require fundamental shifts in the regulatory environment, as well as renewed attention to public-private partnerships and social services. For example, developed countries have 80 per cent of the world's Internet users, while the total international bandwidth for all of Africa is less than that of the city of São Paulo, Brazil (Campbell and Sellbum, 2002).

There is little doubt that sub-Saharan Africa's populations are missing out on the boons of information and communication technology (ICT) in educational management (Bigum, 2000). As a region lagging behind in adoption, use and innovation in the ICT sectors, its people are missing out on a better education and well managed education systems and entities.

ICT has contributed greatly to educational management in schools worldwide (Zhao and Frank, 2003). However, in Kenya Schools hardly use ICTs to manage the quality of output, or to raise teacher productivity, or to reduce costs through analyzing spending. This is attributed to a myriad of challenges facing most schools in Kenya with regard to adoption of ICTs in educational management. This has resulted to a slow rate of adoption of technology despite its promise and potential for use in educational management in schools. Most schools in Kenya have only adopted computers as technical subject and not integrated its use in the teaching and learning. The use of ICTs in educational management is greatly under-emphasized. As such, a more holistic approach requires that schools be receptive and open to the changes ICTs may make, and to the ongoing evaluation of these changes for the schools' purposes. Since there is evidence from countries such as Botswana, Namibia and South Africa that investments in ICTs in education management in schools in some countries are now becoming sufficiently significant for systemic impact (Becta, 2004).

Educational managers need to have basic information on quality of teaching, student and teacher flows, probably also of school supplies, and how much the school as a system is spending on various inputs, in order to make the most basic resource allocation decisions. 
Studies (Becta, 2003; Yang, 2003) indicate that ICT has played an important role in improving management in educational systems through for example availing data widespread to parents and the public at large through central administration websites and in some cases through direct access to central databases by school personnel. As such, this paper examines the challenges facing introduction of information communication technologies in education management in schools in Kenya. The general public ICT literacy is still very low. What is of concern most is that ICT literacy among school manager is also very low, especially those that live in the rural or remote areas parts of Kenya. (Yang, 2003)

\subsection{Benefits of Introducing ICTs in Educational Management}

Education management and development is an intricate process that requires reliable, timely, user-friendly data (Naidu and Jasen, 2002). ICTs can be valuable for storing and analyzing data on education indicators; students' assessments; educational, physical and human infrastructure; and cost and finance (Campbell and Sellbum, 2002). The use of computer related technology is particularly helpful in this field. For instance, administrators and policy makers can construct virtual scenarios around different policy options to determine needs and analyze potential consequences. Each scenario can be analyzed and evaluated systematically, not only in terms of educational desirability, but also in terms of financial afford-ability, feasibility and sustainability over a sufficient period of time to show results.

The same elements of computing and telecommunications equipment and service that have made businesses more efficient and cost-effective can be applied to schools and educational systems. ICTs can help school administrators and school principals to streamline operations, monitor performance and improve use of physical and human resources. More than other technologies, computer related technologies have the potential to support the management of complex, standards-related instructional processes in relatively simple ways. They also can promote communication among schools, parents, central decision makers and businesses thus fostering accountability, public support, and connectivity with market place.

\subsection{Barriers to Adoption of ICT in Education Management Computers in Secondary Schools}

There are currently over 4000 public secondary schools in Kenya and the recent massive increase in primary school enrolment is putting pressure on the demand for and access to secondary schools. (Republic of Kenya, 2007) The Ministry of Education Science Technology remains concerned with the quality of secondary education which is characterized by poor performance in core subjects such as Mathematics and Science. There are obvious benefits for integrating computers into secondary schools as students at this age need to focus on subject-specific content, greater critical thinking skills, scientific inquiry, and Mathematics, science and languages. Students will benefit greatly with the analytical, creative, and collaborative power of computers to map out and analyze assumptions, present ideas, and participate in projects with peers from around the country and around the world. 
Schools should note that foundation skills should be a stepping-stone to using ICTs to enhance teaching and learning objectives. The same ICT integration concepts used in the Teachers Training Colleges model can be adapted for secondary school teachers and students. ICT integration will take teachers and students beyond seeing ICTs as computer studies and computer literacy skills. Although these are important skill sets, they are not sufficient in leveraging the true potential of ICTs to improve creativity, innovation and collaboration -key capacities in the new knowledge economy. In both programmes, the assessment criteria should be made explicit to new users and opportunities to experiment and work with the tools towards achieving these criteria. This will ensure that their new knowledge and skills are conceptualized and more likely retained.

Every school has its own unique context or culture. Higgs (1997) states that most reforms in schools fail because of flawed implementation. Teachers and administrators see minimal gains and much loss in changes that are proposed. The difficulty associated with facilitating change in people's values, attitudes, and behavior is grossly underplayed and often ignored. Siegel (1999) states two reasons why people would want to bring ICTs into schools. The first is the desire of the central planner to the school as modern as the world of tomorrow they conjure into being. Higgs (1997) details how each new development in the popularization of information and entertainment technology (radio, film, television, computers) in society at large brought with it a corresponding insistence that the deployment of this revolutionary machine into schools would, finally, bring the classroom out of the dark ages and unto the modern world. This has not been the case.

According to Siegel (1999) the second impetus has been standardization by modeling schools on factories with the expectation of uniformity of outcome. The weakest link has been found to be the "instructional delivery vehicle" the teacher who once in the confines of a classroom issues of standardization of curricula, of facilities mean very little. This has been the rationale for educational technologists to produce solutions designed not to aid the teacher but to recapitulate, or replace the teacher through the introduction of machines or his/her management style.

The result is the likelihood that innovations in ICT will not be well received by teachers and managers of schools due to conflict with the firmly entrenched traditions. Venkatesh and David (2000) proposed that change in schools means changing attitudes, norms, beliefs, and values associated with the school culture. Researchers have found particular cultural norms that can facilitate school management. Norms such as introspection, collegiality, and a shared sense of purpose or vision combine to create a culture that supports innovation in educational management (Tee, 1993). School managers who had adopted more progressive ICT oriented management styles over time felt that ICTs helped them change, but they do not acknowledge ICTs as the catalyst for change; instead, they cite reflection upon experience, classes taken, and the context or culture of the school (Naidu and Jasen, 2002). For school managers to implement the use of educational technology in a constructivist manner, they must have opportunities to construct pedagogical knowledge in a supportive climate (Taylor and Todd, 
1995).

\subsection{Government Policies on ICT Use in Schools}

The Sessional Paper No. 1 of 2005 captures ICT as chapter VIII. The government appreciates and recognizes that "an ICT literate workforce is the foundation on which Kenya can acquire the status of a Knowledge economy" (Republic of Kenya, 2005:79). Education is seen as the natural platform for equipping the nation with ICT skills .the successful introduction and use of ICT in education and training institutions is seen to play a major role in disseminating skills to the wider society and thus create positive impacts on the economy. In order to change this situation the policy framework states that:-

"Information and communication technology has a direct role to play in education and if appropriately used, ICT can bring many benefits to the classroom as well as education and training processes in general. Its use will provide new opportunities for teaching and learning, including, offering opportunity for more student centered teaching, opportunity to reach more learners, greater opportunity for teacher-to-teacher, and student-to-student communication and collaboration, greater opportunities for multiple technologies delivered by teachers, creating greater enthusiasm for learning amongst students, and offering access to a wider range of courses.. ' (Republic of Kenya, (2005:80)

The Sessional paper notes a number of challenges currently facing access and use of ICT in Kenya which include; 'high levels of poverty that hinder access to ICT facilities, limited rural electrification and frequent power disruptions. Where there is electricity, high costs of Internet provision, costs associated with ICT equipment, inadequate infrastructure and support hinder the application of ICT." In order to achieve the objectives stated for the period 2005-2010 a number of strategies are proposed among them being to "Work with stakeholders to develop a strategy on ICT that addresses its use in all educational institutions and neighbourhoods, incorporating access, content, training of teachers and supply of ICT to the institutions. The KESSP report further envisages the development of e-learning materials and an e-curriculum by using experts in the region to develop local digital content. These are indeed bold steps towards technology integration in schools.

\subsection{Barriers to introduction of ICTs in Schools}

In order to increase and improve the use of ICTs in the schools, a range of obstacles that prevent school managers and teachers from using ICTs effectively need to be overcome. The BECTA Report (2003) identifies the key barriers to using computers as:

- Lack of access to appropriate ICT equipment

- Lack of time for training, exploration and preparation

- Lack of models of good practice in ICT

- Negative attitudes towards ICTs in education 
- Computer anxiety and a lack of confidence

- Fear of change and a lack of personal change management skills

- Unreliable equipment

- Lack of technical, administrative and institutional support.

This BECTA (2003) report further classifies the barriers into the four factors namely a)resource-related factors b)factors associated with training, skills, knowledge and computer experience c) attitudinal and personality factors, and d) institutional and cultural factors.

According to the BECTA (2004) report, barriers identified in the literature can be broadly grouped into two levels: those relating to the institutions (school-level barriers) which are first order barriers and those relating to the individual (manager-level barriers) or second order barriers (Siegel, 1999). Although this may be a useful distinction to make in beginning to address the subject, the literature points to a complex interrelationship between school-level and teacher-level barriers, and between the barriers within those levels(Siegel, 1999).

\subsection{Managerial-Level Barriers}

a) Lack of time — for both formal training and self-directed exploration (Higgs, 1997) and for preparing ICT resources for lessons

b) Lack of self-confidence in using ICT (Farris, 2001)

c) Negative experiences with ICT in the past (Siegel, 1999)

d) Fear of embarrassment in front of pupils and colleagues, loss of status and an effective degrading of professional skills (Zhao and Frank, 2003)

e) Lack of the knowledge necessary to enable managers to resolve technical problems when they occur (Tee, 1993)

f) Lack of personal change management skills (Venkatesh and David, 2000)

g) Lack of motivation to change long-standing pedagogical practices (Campbell and Sellbum, 2002)

h) Perception of ICTs as complicated and difficult to use (Yang, 2003).

\subsection{School-Level Barriers}

a) Lack of ICT equipment (Tee, 2003), and the cost of acquiring, using and maintaining ICT resources

b) Obsolescence of software and hardware (Higgs, 1997)

c) Unreliability of equipment (Butler \& Sellbom 2002; Cuban et. al. 2001)

d) Lack of technical support (Farris, 2001)

e) Lack of administrative support (Siegel, 1999)

f) Lack of institutional support through leadership, planning and the involvement of teachers as well as managers in implementing change (Bigum, 2000)

Where policy makers continue to introduce strategies for ICT, with the intention of increasing its use in schools, such strategies are likely to have an effect on the school level barriers. the 
teacher level barriers are more difficult for policy makers to tackle as it is the teachers themselves who need to bring about the required changes in their own attitude and approach to ICT '’(BECTA, 2004).

Schools are not simply technologies, or are they purely rational in the ways they respond to a given set of conditions. Yang (2003) sees them as organizations seeking nothing so much as their own perpetuity. The entrenched organizations like organisms experience change or the challenge to change most significantly as a disruption, an intrusion, as a failure of organismic defense. Siegel, (1999) observed that a longer timetable allows teachers time to absorb information, try ideas out in their classrooms, and then come back for more discussion. Taylor and Todd (1995) aggress with this view and points out that change frequently fails, because insufficient time is allocated. Other challenges include:

\subsection{Availability of Infrastructure}

Infrastructure for online learning is crucial. Many African countries have a very low base from which to implement ICT interventions in education management in schools. It is estimated that less than 1 per cent of people in Africa uses or have access to the Internet (Bigum, 2000). The figure of 139 students per computer is given for World participants. Listed in order of rank, aspects that inhibit schools from acquiring computers are an absence of electricity, lack of funding, insufficient building space, lack of available and trained staff, and poor security. In Malawi, where most technology infrastructure is government controlled, very low levels of infrastructure for and use of ICTs are found and many government departments have themselves not yet acquired computers. In sub-Saharan Africa, the low teledensity and high costs of installing and maintaining lines are major barriers. Wireless technology is seen as a possibility for rural schools (e.g. in Lesotho). Some countries have implemented pilot projects for wireless technology in rural areas, for example SchoolNet Uganda.

\subsection{Computer Access and Use}

The development of ICTs use in Africa is very uneven. In some countries like South Africa, some sectors of schooling such as management are using computers in education to an extent on par with the developed world, while others are only beginning to explore the possibilities of introducing school networking, for example SchoolNet Malawi. A few are in the start-up phase and most of the developments have been established since 1997.

Thme spent on computers in SchoolNet activities in Africa is generally limited and is related to the type of access and use. Students doing computer studies will spend more 4ime working with the technology than /ther studentS. While teachers and students in schools that have computers learn basic computer skills such as word processing, the integration of computers acr/ss learning areas happens in only a minority of schools.

\subsection{Budgeting for ICTs}

Schools do not budget adequately for maintaining the use of ICTs, and instead dedicate their ICT budgets, where these exist, to the purchase of computers and software. In schools: 'the costs of installation, maintenance and expansion remain hidden unlike in 
the commercial sector where the capital costs of a PC represent only one fifth of the yearly cost of running that PC' (Farris, 2001).

Costs include teacher training, and additional advisory and technical staff as support, both in the technological and pedagogical fields. The Internet for Schools Project in Mozambique, for instance, has both technical and pedagogical coordinators. In addition, hardware, software, telecommunications, infrastructure such as phone lines, and content development have to be budgeted for. Fewer than 5 per cent of South African schools with computers budget for teacher training in the use of ICTs (Higgs, 1997). Initial expenditure has to be considered along with the recurrent costs in order to sustain the use of ICTs in education, in particular the investment in the human capability (Ibid.:46). Budgets tend to derive from fees, fundraising and donations, although in some countries such as Nigeria, government funding is provided. Evidence of the cost effectiveness of spending on ICTs rather than, say, libraries has not yet been established (Higgs, 1997:47).

\subsection{Training in ICT Skills}

The lack of infrastructure may be compensated for by the commitment of the teachers. In some countries projects focus on training for the implementation and sustainability of ICT-based interventions in education. Some see pre-service training as essential, such as the revised national policy on education in Botswana and the aims of SchoolNet Namibia (Bigum, 2000:2) while others consider in-service training the appropriate response. Some hope that "cascade" models will work, like in the Ministry of Education in Gambia (Bigum, 2000:5). Some claim that it has already done so, as in the case of Ghana (Bigum, 2000:6). Others still rely on volunteers, both young and old, to sustain the intervention.

Training goals vary but most are based on training schedules using workshops to cover the various skills. In general, training is seen more in terms of time spent on training than in terms of outcomes such as proficiency in the skills, comfort with the technology or experience in integrating use of the Internet into curricula. Training generally includes basic computer literacy, exposure to the basics of email, search engines, website design and the integration of technology in the classroom, in a concentrated period with groups at various levels of competence

ICTs have clearly made new demands on an already stretched sector while simultaneously offering opportunities in support of current difficulties. The enthusiasm for ICTs may well ultimately be the catalyst for transforming dominant education practices (James, 2001: 29).

Other challenges facing introduction of ICTs in management of secondary schools include (Bigum, 2000):

\subsection{Economic Crisis}

No wonder the biggest obstacle faced by Indonesia regarding ICT is the economic crisis. This condition forces the government to prioritize on short term programs to help improve the economy of the general population through social security net, aids to poor students to decrease drop-out rate, improvement of teacher's welfare etc. As such the government has to postpone various programs that had been planned including the program to support ICT development, The despondent economy also makes the people's spending capacity shrunk, so they prioritize their spending on primary needs such as food and clothing, so that the need to 
use ICT to get access to information become the last choice.

\subsection{Infrastructure}

Another obstacle to the development of ICT in management of schools is the poor condition of the infrastructure, in terms of quantity and also quality. Of course this poor condition affects the ease to get access to information. In connection with the availability of infrastructure it makes access to information costly, which in turn makes the use of ICT low.

\section{Conclusion}

There is need for a comprehensive and forward-looking ICT policy, which creates an enabling framework for the development of ICT in education management in schools in Kenya. The policy would guide proper deployment of ICT in education. Local expertise, possibly from members of the specialized committee, need to be involved in this process.

From this paper, the most obvious policies inside education that could stimulate more use of ICT in educational management would be widespread training of secondary school administrators and university students in using ICT-based management tools. By making such training part and parcel of a general education preparation, the younger generation of teachers and education administrators would be highly trainable in using ICT in educational; management in schools.

Time and research may foreground new perspectives. One line of thinking is that Africa cannot afford to exclude itself from globalization and global connectedness and has to "get on board" with ICTs, while others express the concern that connectivity and technology compete with more pressing priorities. Exclusion is a concern not only nationally, but also internationally. With exclusion go fears of increased antagonisms between rich and poor, young and old, urban and rural and boys and girls, across and within nations. All these tensions threaten the potential success of school networking initiatives and pose the biggest challenge for practitioners and decision makers. It is against this background, with its particular challenges and constraints, that the evaluation of the role of ICTs in educational management in selected schools in Kenya becomes a priority.

\subsection{Way Forward}

More research is needed to evaluate the influence of ICTs on the overall operation of the school as a system. Literature suggests that the more systemic the changes, the more effective ICTs will be in education. This systemic approach includes uses of ICTs in administration and management, and in broader management of the education system. Data can be more easily collected from schools, for instance, and educators can have an easier access route to government departments where two-way communication is possible. A more holistic approach should be adopted which requires that schools be receptive and open to the changes ICTs may make, and to the ongoing evaluation of these changes for the schools' purposes. 


\section{IIMacrothink}

\section{References}

BECTA (2003). What Research Says about Barriers to the Use of ICT in Learning. Retrieved from www.becta.org.uk/research.

BECTA (2004). A Review of the Research Literature on Barriers to the Uptake of ICT by Teachers. Retrieved from www.becta.org.uk/research

Bigum C. (2000). Solutions in Search of Educational Problems: Speaking for Computers in Schools. [Electronic Version] Educational Policy, 12 (5), 586-596.

Campbell D. \& Sellbom, M. (2002), 'Barriers to Adopting Technology for Teaching and Learning', Educase Quarterly, 25 (2), 22-28.

Farris, E. (2001). Internet Access in US Public Schools and Classrooms 1994-2000. National Center for Educational Statistics.

Higgs, J. (1997). 'Barriers to the Effective Use of Technology in Education', Journal of Educational Computing, 17 (4), 385-395.

Naidu S.D., \& Jasen, C. (2002). The Experience of Practitioners with Technology Enhanced Teaching and Learning [Electronic Version]. Educational Technology \& Society, 5 (1), 23-34.

Republic of Kenya, (2007). Ministry of Education Science and Technology Report. Nairobi, Government Printing Press.

Republic of Kenya, (2005). Sessional Paper No.1 of 2005. Nairobi, Government Printing Press.

Siegel, J. (1999). The State of Technology and Educational Management in Schools: [Electronic Version] Electronic Learning, 14 (8), 43-53.

Taylor, S. and Todd, P. (1995). "Understanding Information Technology Usage: A Test of Competing Models," [Electronic Version] Information Systems Research, W. (1993), 'The Role of Beliefs in the Use of Information Technology: Implications for Teacher Education, or Teaching the Right thing at the Right Time', [Electronic Version] Journal of Information Technology for Teacher Education, 2 (2), 139-153.

Tee, W. (1993). 'The Role of Beliefs in the Use of Information Technology: Implications for Teacher Education, or Teaching the Right thing at the Right Time', [Electronic Version] Journal of Information Technology for Teacher Education, 2 (2), 139-153.

Venkatesh, V. and David, S (2000). "A Theoretical Extension of the Technology Acceptance Model: Four Longitudinal Field Studies," [Electronic Version] Management Science, 
46, 186-204.

Yang, S. (2003). Teachers' Perception of Use of Student Performance Information: Technology Acceptance Model. An Unpublished Thesis. The University of Texas at Austin. $\quad$ Retrieved $14^{\text {th }} \quad$ March 2006 from www.lib.utexas.edu/etd/d/2003/yangsk03/yangsk03.pdf\#page=3.

Zhao, Y. and Frank, KA (2003). Factors Affecting Technology Uses in Schools: An Ecological Perspective [Electronic Version]. American Educational Research Journal, 40(4), 807-840. 